\title{
Detection of Coastal Region Sea Ice Decay from Orthorectified RADARSAT-1 ScanSAR Imagery: A Case Study of Bering Strait and Norton Sound, Alaska
}

\author{
X. Zhou ${ }^{1 *}$, N. B. Chang ${ }^{2}$, and S. $\mathrm{Li}^{3}$ \\ ${ }^{1}$ Department of Geophysical Engineering, Montana Tech of the University of Montana, $1300 \mathrm{~W}$ Park Street, Butte, MT 59701, USA \\ ${ }^{2}$ Department of Civil and Environmental Engineering, University of Central Florida, 4000 Central Florida Blvd., Orlando, FL 32816, USA \\ ${ }^{3}$ Geophysical Institute, University of Alaska Fairbanks, P. O. Box 757320, Fairbanks, AK 99775-7320, USA
}

\begin{abstract}
Application of SAR images to detect the onset of breakup and dynamic decay process of coastal sea ice was investigated, using a time series of RADARSAT-1 C-band scanning SAR images of the areas around Seward Peninsula coastal region, Alaska, including Bering Strait and Norton Sound. Satellite image analyses mainly include a time series feature space images composed of radar backscattering coefficient versus look angle derived from RADARSAT-1 amplitude images covering both coastal sea and land area. It was found that the feature space images have a single mode before the decay and breakup of the coastal sea ice, and have multiple modes when large-scale open water first appears until the coastal sea ice disappears completely. The mode patterns in the feature space images can then be determined by the water surface roughness caused by the wind field. The single-mode phenomenon before ice melting is thought to be due to a similarity of the backscattering of snow cover on sea ice and land surface due to the common coverage by snow and ice. The appearance of multiple modes is due to the differences in backscattering of sea ice surface at various decaying stages or open water with different wave roughness due to wind effect, and the land surface with snow and ice cover with different melting conditions once the melting or decay starts and proceeds. The feature space images reported here can be used as a useful tool in detection of decay of coastal sea ice and landfast ice in the field of sea ice dynamics as the imaging radar technology is weather independent, providing information of coastal ice on a regular basis.
\end{abstract}

Keywords: Coastal sea ice, feature space image, multiple modes, SAR, single-mode

\section{Introduction}

Sea ice buildup and decay in coastal regions have a great effect on the local human activities such as marine navigation and transportation, local economy such as fishing and oil and gas exploration and production, and even local ecosystem. In view of economical marine navigation and transportation, prompt knowledge of the timing of the opening of the Arctic seaway will help save money and time for North Atlantic ships going to East Asia because the Arctic seaway is about one-quarter distance shorter than the route through the Panama and Sues Canals. Grounded ice and ice ridges formed at the border of fast ice can pose as a great barrier for offshore oil and gas exploration (Divine et al., 2004). In the aspect of local ecosystem, it was found that the algal assemblage north of Drygalski Ice Tongue, in the western Ross Sea, Antarctica, is most closely associated with Fragilariopsis curta (a diatom common in stratified ice edge zones), suggesting that water column seeding by species melting out of coastal sea ice is important in the area (Cunningham and Leventer, 1998). Ice edge upwelling in the marginal ice zone can break down stratification formed from previous melting season and bring up nutrients to the photic zone for the coming spring phytoplankton bloom (Okkonen and Niebauer, 1995). A number of spe-

\footnotetext{
* Corresponding author: xzhou@mtech.edu
}

cies of marine birds and mammals that need open water, including leads, to access the benthos for feeding also rely on pack ice to reduce winds and dampen waves to live among fragmented floes in the marginal ice zone (Hunt, 1991; Hunt et al., 1996; Stirling, 1997; Bump and Lovvorn, 2004). The spacing, size, and duration of open water will directly affect the foraging activities or even the survival of these spices. During the buildup, decay, and breakup time, dynamic motion of massive sea ice and landfast ice can jeopardize the oil and gas platforms and ships and disrupt transportation schedule. On the other hand, buildup and decay patterns of coastal sea ice may also indicate the climate and oceanic current dynamics. Accurate and effective detection and monitoring can provide useful information and feedback for climate and oceanographic modeling and prediction.

The date of onset and duration of break-up in the coastal fast ice can vary significantly from year to year. Conventional methods in determining the date of the onset and completion of breakup of fast ice include the last observation of the stability of spring configuration of the fast ice and a threshold of the total area of fast ice. These methods are largely based on the areal estimation and ice type discrimination. Error can usually be $7 \sim 12 \%$ if the ice area is derived from the Special Sensor Microwave Imager (SSM/I) data (Devine et al., 2004). Moreover, the definition of onset and completion of the decay of coastal sea ice is very vague, as different researchers define 


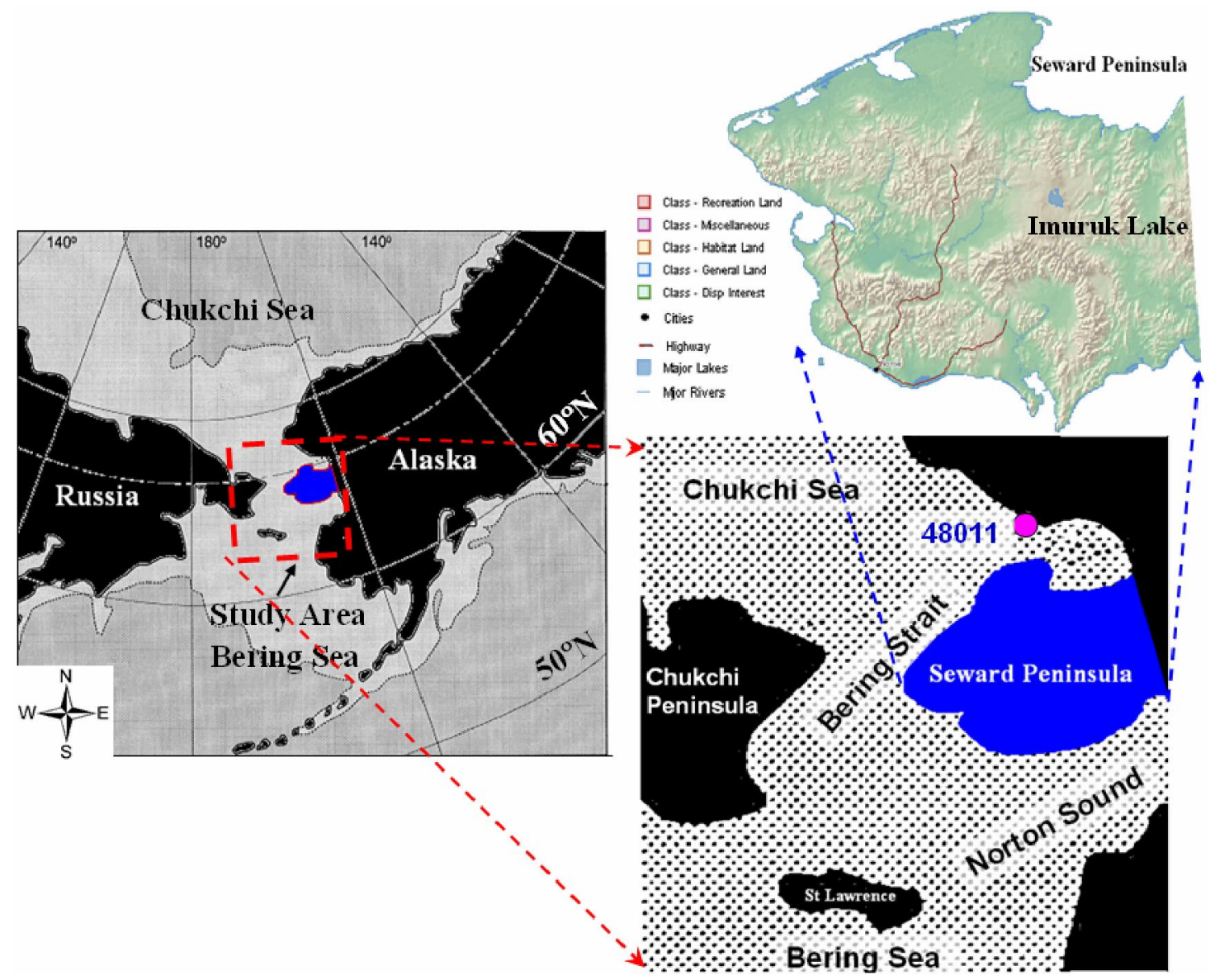

Figure 1. Study areas including Seward Peninsula and its coastal areas, which contain the Bering Strait and Norton Sound (The buoy Station 48011 of National Data Buoy Center (NDBC) of NOAA is also shown, http://www.nodc. noaa.gov/BUOY/bakw.html).

their own thresholds.

Multiple forcings have been identified to impact the onset of ice breakup, and decay of coastal sea ice. Such forcings include turbulent heat flux in the wind, air temperature, precipitation and ice thickness distribution (Bilello, 1980; Crocker and Wadhams, 1989; Flato and Brown, 1996; Divine et al., 2004), riverine sensible heat and runoff from river recharge (Searcy et al., 1996; Dmitrenko et al., 1998), shear and compression stresses caused by both wind and oceanic currents (Volkov et al., 2002). However, the onset of ice melting and decay process are still unpredictable, some results are even contradictory with each other (Brown and Cote, 1992; Flato and Brown, 1996; Divine et al., 2004).

Therefore, detecting and monitoring the buildup and decay accurately and efficiently in real time or near-real time become imperative for the safety and economy reasons in marine transportation and navigation in coastal regions, oil and gas exploration and production, cold region ecosystem, and climate and oceanographic studies. Real time observation and quick assimilation of observation data into forecast system are still the main means for coastal region weather forecasting and warning. Remotely sensed data are the major observations due to the harsh (cold, cloudy, and dark) environment and economic consideration. Apart from the all-weather coastal radar observation systems, optical systems from aircrafts and satellites, buoy-mounted instrumentation and automatic drifting ice stations, observations from ships and coastal meteorological stations, space-based radar systems can also provide repetitive and useful sources for such observations. Synthetic aperture radar (SAR) images offer a robust way of observing ice in the often dark and cloud-covered polar areas in cold seasons. As radar can penetrate the clouds and is independent of the daylight, it can provide real time data for weather forecast systems (Onstott, 1992).

The purposes of this paper are: (1) to investigate the relationship between the radar backscattering coefficient and look angle from radar images consisting of both land surface and sea surface at various development and decaying stages during the life of coastal sea ice from early spring to late fall; and (2) to explore the possibility of using such a relationship as a 
tool for efficient and decisive monitoring of the onset of decay and breakup of costal sea ice and the associated process using satellite radar imagery, based on its intrinsic capability of weather independence.

The rest of this paper is organized as follows: In section 2, the study site will be described. In Section 3, RADARSAT ScanSAR images and buoy data from the National Oceanic \& Atmospheric Administration (NOAA)'s National Data Buoy Center (NDBC) are described. In section 4 , the image processing and analysis procedures are presented. In Section 5, the results of radar image analysis on the effective detection and monitoring of the breakup and decay of the fast ice are given, followed by a discussion. Conclusions are drawn in Section 6 .

\section{The Study Site}

The study site is selected as the coastal regions around Seward Peninsula of Alaska, including Seward Peninsula, Bering Strait, and Norton Sound as shown in Figure 1.

Seward Peninsula (upper right panel in Figure 1) of the central Beringia locates at the north western Alaska. Geologically, the western part of Seward Peninsula is Paleozoic sedimentary rocks of York Mountains. The rest of Seward Peninsula is mainly of blueschist-greenschist facies Paleozoic to Precambrian metasedimentary rocks of Brooks Range schist belt and Seward Peninsula (Patrick and Lieberman, 1988). Studies on paleosols in Seward Peninsula by Höfle and Ping (1996) show that they are permafrost soils developed in calcareous loess and have roots present throughout. Colors are predominantly grayish, either reflecting original loess color or periodic saturation of the soils (possibly caused by the permafrost environment). Active layer thicknesses ranged from 32 to $64 \mathrm{~cm}$. Morphological and chemical data suggest that soil development was weak and confined to organic matter accumulation, and hydrolysis of iron. Soil-forming conditions on northern Seward Peninsula during the last glacial maximum were severe, and combined with fairly continuous loess deposition they resulted in weakly developed, nutrient-rich soils.

Lying in north-central Seward Peninsula is the Imuruk Lake (upper right panel of Figure 1), a large shallow lake of bout $13 \mathrm{~km}$ long and less than $3 \mathrm{~m}$ deep. Analysis of the hydrologic regime indicates that much of the water draining into the lake is lost by evaporation; smaller quantities are lost by discharge through the outlet, the Kugruk River (not shown in Figure 1), and by leakage into the lava flows along the lake shore. Changes in the duration and temperature of the summer ice-free season would result in changes in the amount of water lost by evaporation and thus in appreciable changes in lake level (Hopkins, 1959). Imuruk Lake is frozen in winter and ice free in summer.

In the summer, the Bering Sea is generally free of ice. Seasonal pack ice forms in the sea north to St. Lawrence Island in late fall and early winter. The prevailing seasonal northerly wind forcing at typical speeds of $17 \sim 22 \mathrm{~km} \cdot \mathrm{day}^{-1}$ to as high as $28 \sim 32 \mathrm{~km} \cdot \mathrm{day}^{-1}$ (Overland and Roach, 1987) moves the seasonal pack ice southward at $15 \mathrm{~km} \cdot \mathrm{day}^{-1}$ (Niebauer et al., 1999). As the pack ice grows and advances, it is compressed on the north side of St. Lawrence Island, resulting in leads that propagate southward from the eastern and western ends of the island. Polynyas (ice-free areas) extending typically 20 to $40 \mathrm{~km}$ south of the island often form in winter (Pease, 1987). Leads continually open and close, depending on the temperature and oceanic current, wind field and wind-driven convergence or divergence. The maximum sea ice cover generally occurs in March or early April, and the minimum sea ice occurs in September. These characteristics of the study site should be considered when the SAR ice images are interpreted.

\section{Data Sources}

\subsection{RADARSAT Scanning SAR Images}

Synthetic aperture radar (SAR) imagery is currently the most widely used satellite imagery to describe ice conditions on a scale relevant to breakup and decay of costal sea ice because of its high enough resolution (12.5 to $100 \mathrm{~m}$ ) and capability of acquiring images regardless of solar illumination and weather conditions, which is essential for analyses in the polar and subpolar regions during winter (Onstott, 1992). A time series of ScanSAR C-band (wavelength of $5.66 \mathrm{~cm}$ ) images from RADARSAT-1 in 2001 are selected for this study based on the availability of SAR images and concurrent weather data from buoy station located in the Norton Sound (see section 3.2). Full-resolution imagery from Canadian RADARSAT-1 was provided by Alaska SAR Facility (ASF) and processed for a $500 \mathrm{~km}$ by $500 \mathrm{~km}$ swath of the same location, during the approximately same times of the day. Approximate coordinates of the swath boundary were $62^{\circ} \mathrm{N}, 67$ ${ }^{\circ} \mathrm{N}, 159^{\circ} \mathrm{W}$, and $176^{\circ} \mathrm{W}$ (Figure 1). We analyzed 39 images acquired from both ascending (south to north) and descending (north to south) satellite orbit modes on 39 individual days covering a period from April 20, 2001 to August 25, 2001. Information on SAR radar backscattering coefficient calibration, data specifications, and processing algorithms for ScanSAR imagery, can be found at http://www.asf.alaska.edu.

\subsection{Buoy Data}

Standard meteorological data, especially wind intensity and direction data used for this study are provided by the NOAA's National Data Buoy Center (NDBC) (http://www. ndbc.noaa.gov/historical_data.shtml\#stdmet). Within our study area, data in 2001 are available from Station 48011 (67 $34^{\prime}$ 54'N, 164'11'06"W) at Red Dog Mine, Seward Peninsula, Alaska. Weather data from Station 48011 are available from July 13, 2001 to October 6, 2001. These data are hourly data, including wind speed and wind direction (the direction the wind is recorded in degrees clockwise from geographic north) from an anemometer at a height of $5 \mathrm{~m}$ above site elevation (sea level), peak 5 or 8 second gust speed, significant wave height (Steele and Mettlach, 1993), mean wave direction corresponding to energy of the dominant wave period (the period of time with the maximum energy), air temperature at a 
height of $4 \mathrm{~m}$ above sea level, and sea water temperature at a depth of $0.6 \mathrm{~m}$ below sea level.

\section{Data Processing}

The RADARSAT-1 images for this study were ordered from the Alaska SAR Facility (ASF) of University of Alaska Fairbanks. For this study, 39 Level 1 RADARSAT ScanSAR images of 39 days were acquired from April 20 to August 25, 2001 for the study area (Figure 1). Of the 39 ScanSAR images, 19 were acquired in descending mode in the morning (local time between 9:33 AM and 10:02 PM), and 20 were acquired in ascending mode in the afternoon (local time between 8:30 PM and 8:51 PM). RADARSAT-1 operated in C-band (5.3 $\mathrm{GHz}$ or $5.66 \mathrm{~cm}$ ) in $\mathrm{HH}$ polarization mode. The data ordered were delivered in raw Level 1 CEOS format. These raw data are radar backscattering amplitude images. These amplitude RADARSAT-1 ScanSAR images were converted to radiometrically calibrated radar backscattering coefficient $\sigma^{0}$ images in GeoTIFF format using the Alaska Satellite Facility Data Conversion Tool (version 1.1.8) (available at: https://software. asf.alaska.edu/convert/index.html). These images were then georegistered (referenced to ground coordinates). We projected the images in the Universal Mercator System (UTM) with the World Geodetic System 1984 datum (Kumar, 1993), and warped (transformed) them with a first-degree polynomial with nearest neighbor resampling (Jensen, 2005).

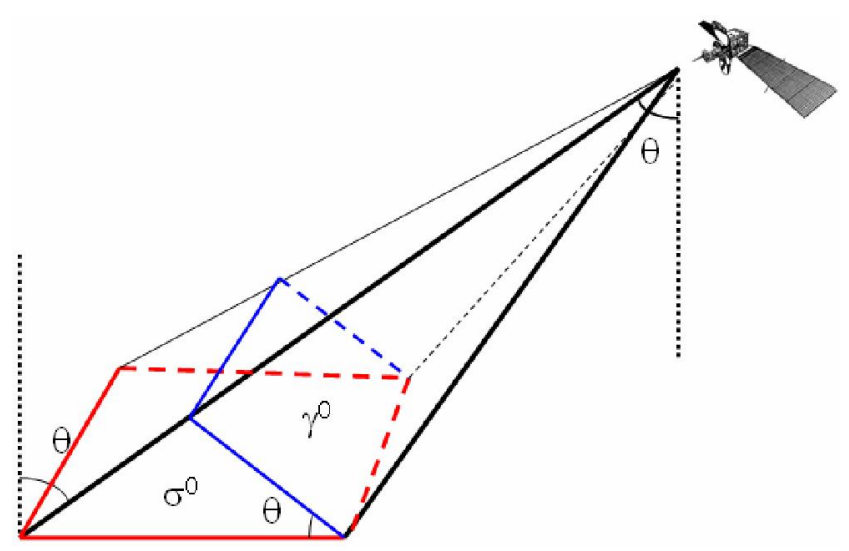

Figure 2. The relationship between the look angle $(\theta)$ and the projections of backscattering coefficient on the ground range (sigma $\sigma^{0}$ ) and on the vertical plane to the slant range (gamma $\left.\gamma^{0}\right)$.

Look angle image was derived from the absolutely calibrated SAR backscattering coefficient image (in slant-range presentation) and a geocoded SAR backscattering image (in ground-range presentation) as shown in Figure 2, which shows projections of backscattering coefficient on the ground (sigma naught $\sigma^{0}$ ) and on the plane perpendicular to the radar beam (gamma naught $\gamma^{0}$ ). The look angle for each pixel is:

$\theta=\cos ^{-1}\left(\sigma^{0} / \gamma^{0}\right)$
To obtain the look angle for each image, the ASF convert tool is used to generate backscattering coefficient projections, sigma naught $\sigma^{0}$ and gamma naught $\gamma^{0}$ from the same amplitude image.

The $500 \mathrm{~km} \times 500 \mathrm{~km}$ image swath covering the coastal region of Seward Peninsula was subdivided into two strata: land and sea, based on a land cover mask. Although all images are within the study area and cover both land and sea, their exact boundaries are slightly different from one another. Land cover masking is first performed for each image. Within sea stratum, sub-strata are derived for ice and open water if there is a breakup of sea ice or appearance of leads or polynya. For open water, further subdivision of calm or rough surface conditions is made based on wind and wave height data from NOAA's buoy data for each of the satellite orbit modes (descending or ascending). Then the relationship between backscattering coefficient $\sigma^{0}$ and look angle that corresponds to the land, sea ice, calm open water or rough open water is presented in a 2D space feature image consisting of $\sigma^{0}$ and look angle. Each relationship between $\sigma^{\circ}$ and $\theta$ is called a mode in a single feature space image. These modes capture various surface types and are used in monitoring the coastal sea ice and open water conditions across an image to study the breakup and decay of coastal ice.

\section{Results and Discussions}

The time series of ScanSAR images in descending mode are shown in Figure 3. The first column (Figures 3a, 3d and $3 \mathrm{~g}$ ) shows the original SAR backscattering coefficient images, the middle column shows the feature space images of backscattering coefficient versus look angle, and the third column shows the interpretation and characteristic mode of the feature space images.

On April 20, the sea ice was consolidated, except for a few latent heat polynyas at the south-eastern part of the image (between Chukchi Peninsula and St. Lawrence Island). Between the fast ice and the drifting pact ice, there often exists a narrow and recurrent shear zone, induced by off-shore winds and circulating currents, causing shear stress between landfast ice and drifting pack ice. Quasi-stationary open water or polynyas often occurs in this shear zone, exposing the sea water to the cold air. Losses of significant amounts of latent and sensible heat in this region often induce the new ice formation and deep cold and saline water production. This turns such shear zones into ice and deep water factories (Divine et al., 2004; Chapman, 1999; Dethleff et al., 1998), pumping up particulate materials and nutrients onto the ocean surface (Reimnitz et al., 1992; Korsnes et al., 2002). If we ignore the pixels of polynyas in the feature space image of backscattering coefficient versus look angle (right to the April 20 SAR image), there is only one near-linear cluster (Figure 3b), showing the decreasing of the backscattering coefficient with increasing look angle. We call this near-linear feature in the feature space "land and consolidated ice" mode. Such a single mode structure of the feature space image is an indicator that the sea ice in the coastal region was consolidated. According to Kwok et 

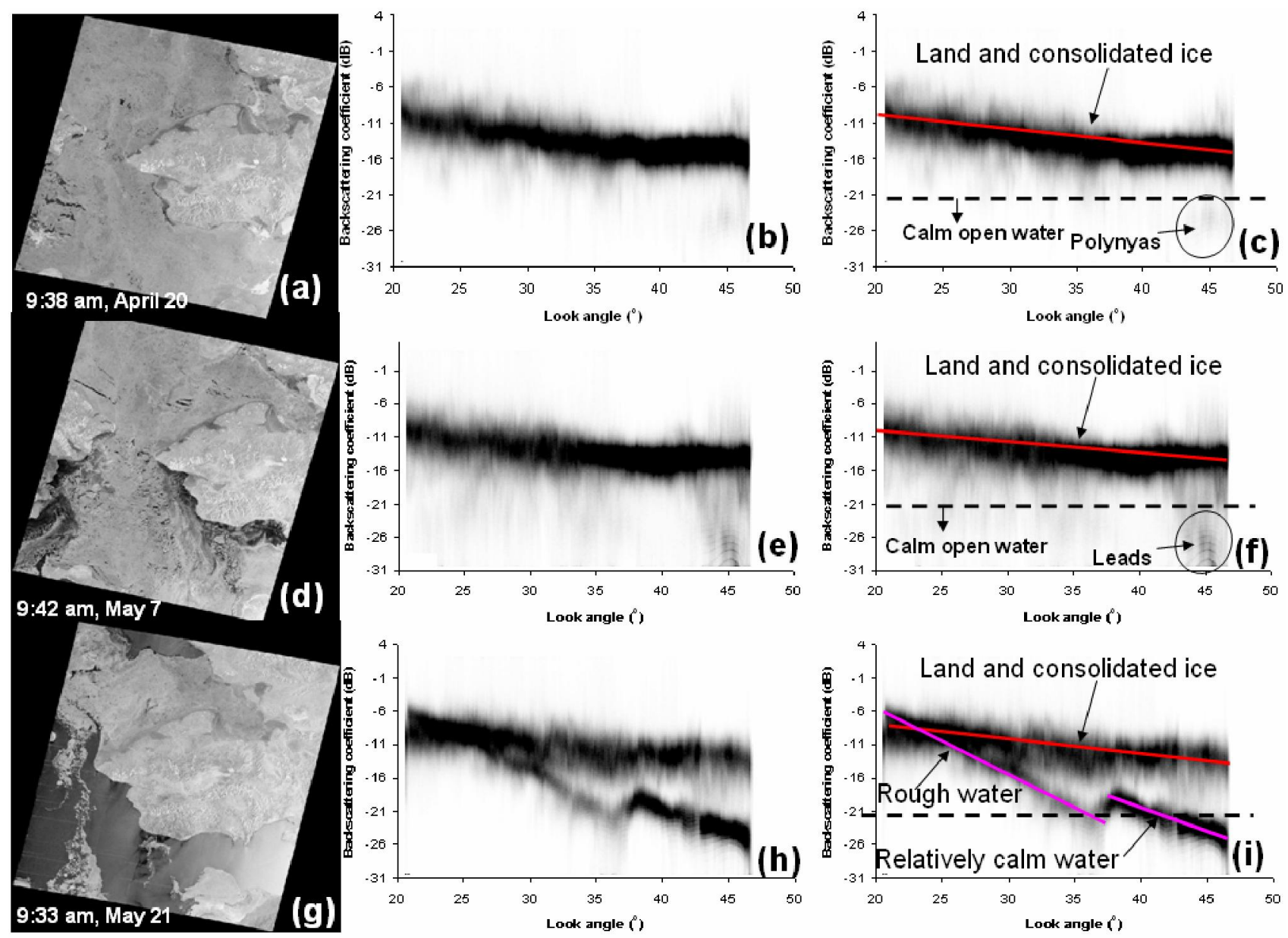

Figure 3. RADARSAT-1 ScanSAR images in descending mode (left column from top to bottom) and the feature space images (middle and right columns from top to bottom) corresponding to April 20, May 7, and May 21, 2001.

al. (1992) and Bump and Lovvorn (2004), the pixels with $\sigma^{0}$ values $\leq-22 \mathrm{~dB}$ indicate calm open water due to specular reflection. The threshold of $-22 \mathrm{~dB}$ for calm open water was first derived for European Remote Sensing (ERS) SAR images that have look angle between $19^{\circ}$ and $26^{\circ}$. For larger look angles, it can be lower. For rough open water, the real $\sigma^{0}$ value is much higher. The points in the feature space images (Figure 3c) below the characteristic line for calm open water are for open water and shadowed pixels, which have backscattering coefficient $<-22 \mathrm{~dB}$. Pixels of the polynyas in the SAR image of April 20, 2001 are clustered at the bottom right, but below the characteristic line for calm open water.

Up to May 7, 2001, the area of polynyas increased and a new water lead appeared at the southern coast of Seward Peninsula. Thus in the feature space image (Figures 3e and 3f), more pixels appear in the space below the characteristic line for calm open water. However, except for pixels from these polynyas, the feature space image only shows one single mode. This mode is very similar to the mode of April 20, 2001, except for some micro-structural differences. Thus, the coastal sea ice was still consolidated.
By May 21, 2001 (Figure 3g), the northerly wind compacted ice in the sea to the north of Seward Peninsula, ice seems to be always consolidated up to end of May. Bering Straight was still ice bonded. The open water area between Chukchi Peninsula and St. Lawrence Island continued to enlarge. Overall, the pixels are separated into three clusters (Figure $3 \mathrm{~h}$ ), three modes appear (Figure 3i). Compared with Figure $3 \mathrm{c}$ and Figure $3 \mathrm{f}$, there are two new modes in Figure $3 \mathrm{i}$. Both modes are open water modes: the one at the left side in the feature space image (Figure 3i) is the rough open water mode, corresponding to the pixels of medium brightness at the lower right side of the SAR backscattering coefficient image (Figure $3 \mathrm{~g}$ ), the other at the lower right corner in the feature space image is the relatively calmer open water mode, corresponding to much darker pixels at the left side of the backscattering coefficient image. For the open water surface, pixels of near-range were rough due to wind. Different roughness between the sea of far coast and that of near coast of Seward Peninsula makes it possible to separate the relative calm water from rough water. Even though, there are some pixels connecting the relatively calm water mode and the rough water 

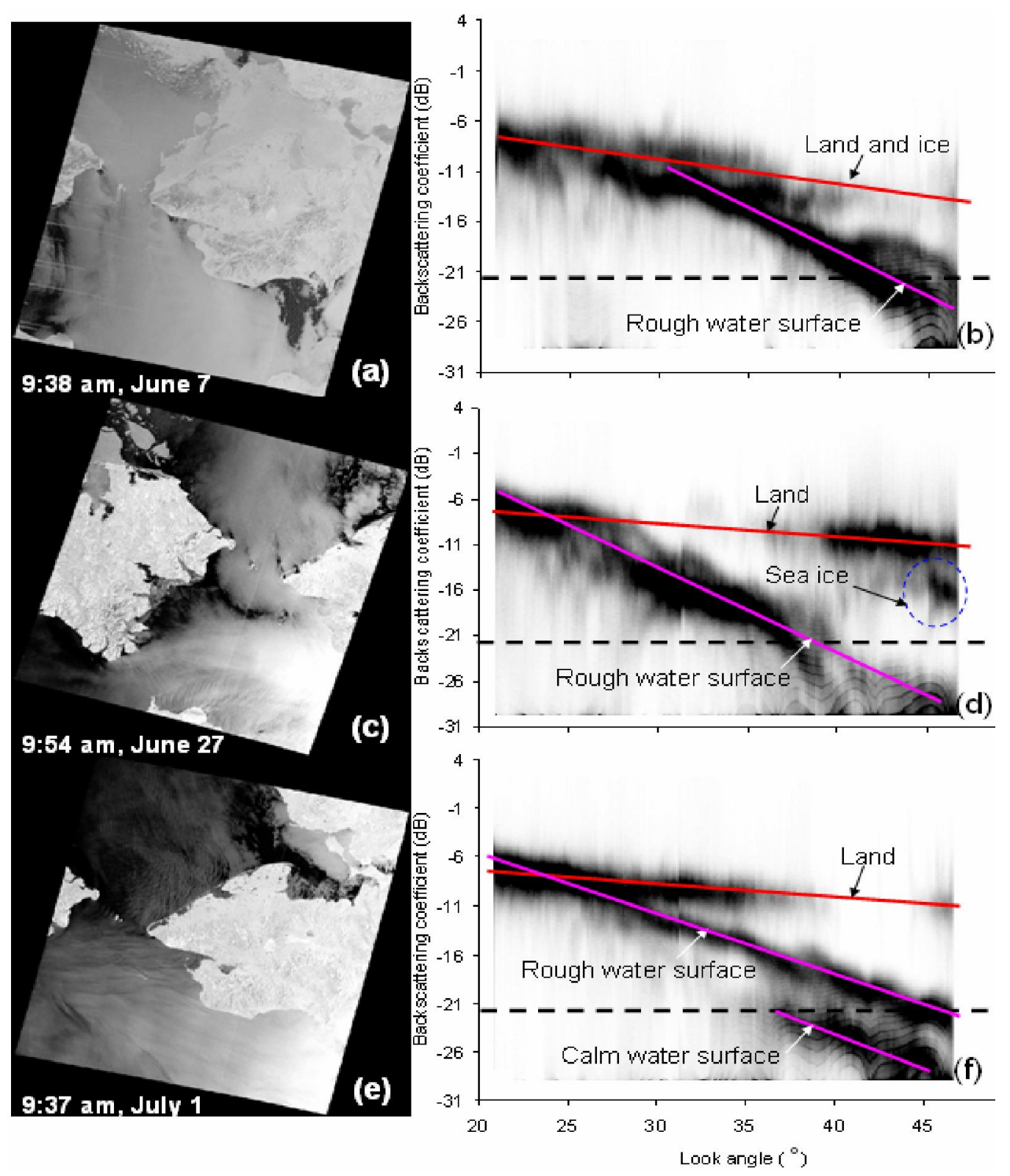

Figure 4. RADARSAT-1 ScanSAR images in descending mode (left panel from top to bottom) and the feature space images (right panels from top to bottom) corresponding to June 7, June 27, and July 1, 2001.

mode, corresponding to the transition area from rough water area to calm water area. In any case, the appearance of open water mode is a good indicator of the breakup and decay of coastal sea ice.

From the time series of the feature space images shown in Figure 3, we can see that in 2001, the breakup of fast ice in the Seward Peninsula coastal region, including Bering Strait and Norton Sound began at some time between May 7, 2001 and May 21, 2001. In comparison, the time of break-up of fast ice in the Kara Sea usually starts in May-June, outside the line of ice ridges and in the vicinity of the $\mathrm{Ob}$ and Yenisei Rivers' mouths. The more stable part in the eastern Kara Sea breaks up in July or the first 20 days of August (Divine et al., 2004). Considering the very dynamic nature of the sea at Bering Straight and Norton Sound due to wind and oceanic currents, breakup and decay of coastal sea ice around Bering Straight and Norton Sound can be earlier than other Arctic regions. Overall, observation from RADARSAT-1 ScanSAR imagery that the breakup and decay of coastal sea ice in Bering Straight and Norton Sound occurred between May 7 and May 21 in 2001 is consistent with the observations in other Arctic regions.

Figure 4 shows a sequential SAR images following the ice break in May. On June 7, 2001, there was still sea ice 
along the coast of northern Seward Peninsula. However, there was no more sea ice in the Bering Sea south to the Seward Peninsula and the Bering Straight was completely ice-free. The corresponding feature space image (Figure 4b) shows that there are two modes: land and ice mode and rough water surface mode. At this time, the land mode and ice mode can not still be separated. The rough water surface mode can extend well into space above the characteristic line of calm open water, depending on the roughness of water surface due to wind field.

On June 27, 2001, wet land surface showed very strong backscattering (Figure 4c). To the north of the Chukchi Peninsula in the Chukchi Sea, there were floes of first year sea ice. The backscattering coefficient of the sea ice is smaller than that of the land of both Chukchi and Seward peninsulas. In the feature space image (Figure 4d), the modes of land and sea ice are separated. The mode of rough water surface shows complicated structure, depending on the degree of surface roughness of the pixels along the same look angle. But we can see that the pixels of the open water are still clustered along a near-linear line, though the width of this near-linear feature is larger than that shown in Figure 3(i). The backscattering coefficient of rough water surface varies so greatly that it can even be greater than that from any other surfaces. This can be seen from the left end of the mode of rough water surface at near-range (small look angle) (Figure 4d) and the brightest area to the south of the Seward Peninsula (lower right corner of Figure 4c). Pixels of water surface with such roughness are often confused with pixels of sea ice in ice classification. The roughness water surface mode as shown in feature space (Figures $4 \mathrm{~b}$ and $4 \mathrm{~d}$ ) will help us identify if a pixel should be classified as open water or sea ice.

On July 1, 2001, no sea ice is seen in the backscattering coefficient image (Figure 4e). In the corresponding feature space image, there are three modes: land surface, rough water surface, and calm water surface. Land surface mode generally has higher backscattering coefficient than other surface types. Rough water surface and calm water surface modes are separated. This separability is mainly due to the different wind field intensities in the Chukchi Sea north to the Chukchi Peninsula and the Bering Sea, especially in the area of Norton Sound and the viewing geometry of the RADARSAT-1 satellite. At the far-range look angles, the pixels of higher backscattering coefficient in the Bring Sea and those of lower backscattering coefficient in the Chukchi Sea are prominently contrasted. Therefore, the roughness surface mode and the calm water surface mode are separated.

To investigate the consistency of the interpretation following the guide lines discussed above using mode patterns in the feature space image with observation of other sources, we look at the SAR image of July 18, 2001 (Figure 5a) and the buoy data from the Station 48011 of National Data Buoy Center, NOAA. The SAR backscattering coefficient image is shown in Figure 5a and the corresponding feature space image in Figure 5b. Based on the discussion above, we have two main modes in Figure 5b: land surface mode and rough water surface mode. A cluster of calm water pixels lies below the rough water surface mode at far range (look angle between $40^{\circ}$ and $47^{\circ}$ ). The calm water surface area corresponds to the south-west corner in the image of Figure 5a. Backscattering coefficient from the rough water surface is smaller than that from the land surface. Compared with the backscattering coefficient amplitude of open water pixels in the images of June 27 and July 1 (Figures 4c and 4e), we can see that the water surface roughness of July 18 is smaller than that of June 27 and July 1.

Table 1 shows the hourly weather data at 10:00am of July 18, 2001, when the RADARSAT ScanSAR image was acquired (see Figure 5). From these data we can see that the northerly wind was at a speed of $4.9 \mathrm{~m} / \mathrm{s}$, with peak 5 or 8 second gust speed of $6.1 \mathrm{~m} / \mathrm{s}$, the significant wave height was $0.93 \mathrm{~m}$, moving southward. The available wave height data at
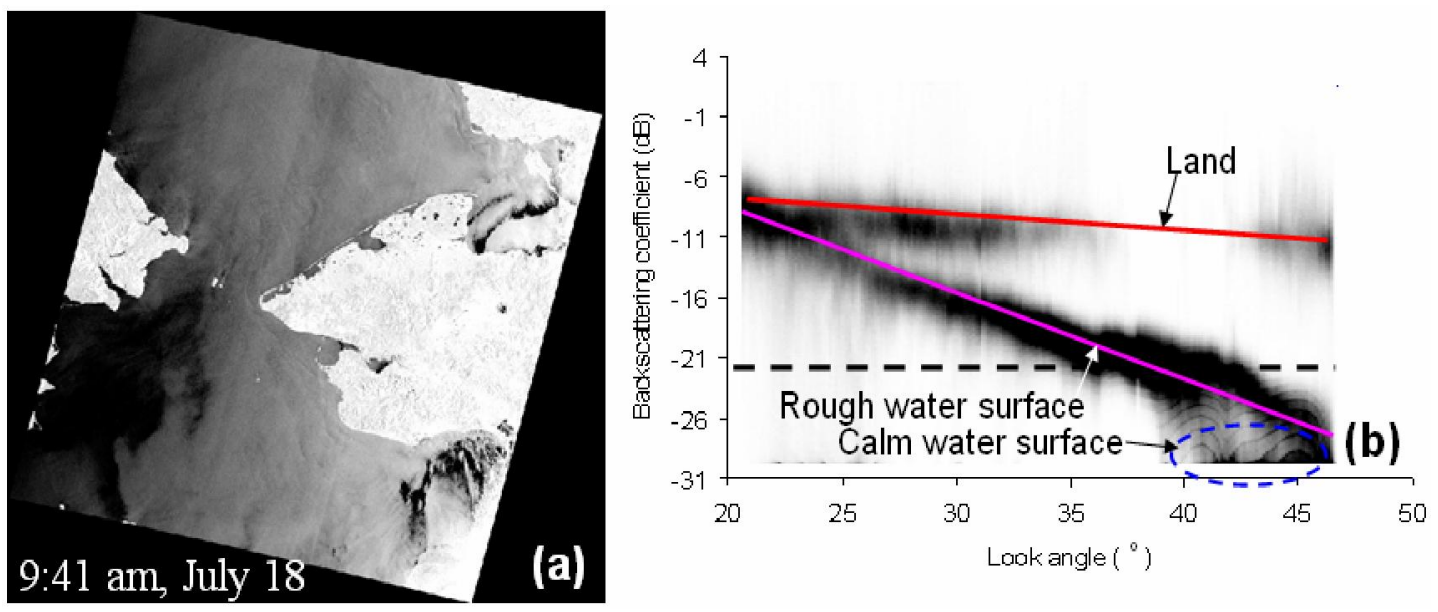

Figure 5. (a) RADARSAT-1 ScanSAR backscattering coefficient image in descending mode, and (b) the corresponding feature space image of July 18, 2001. 


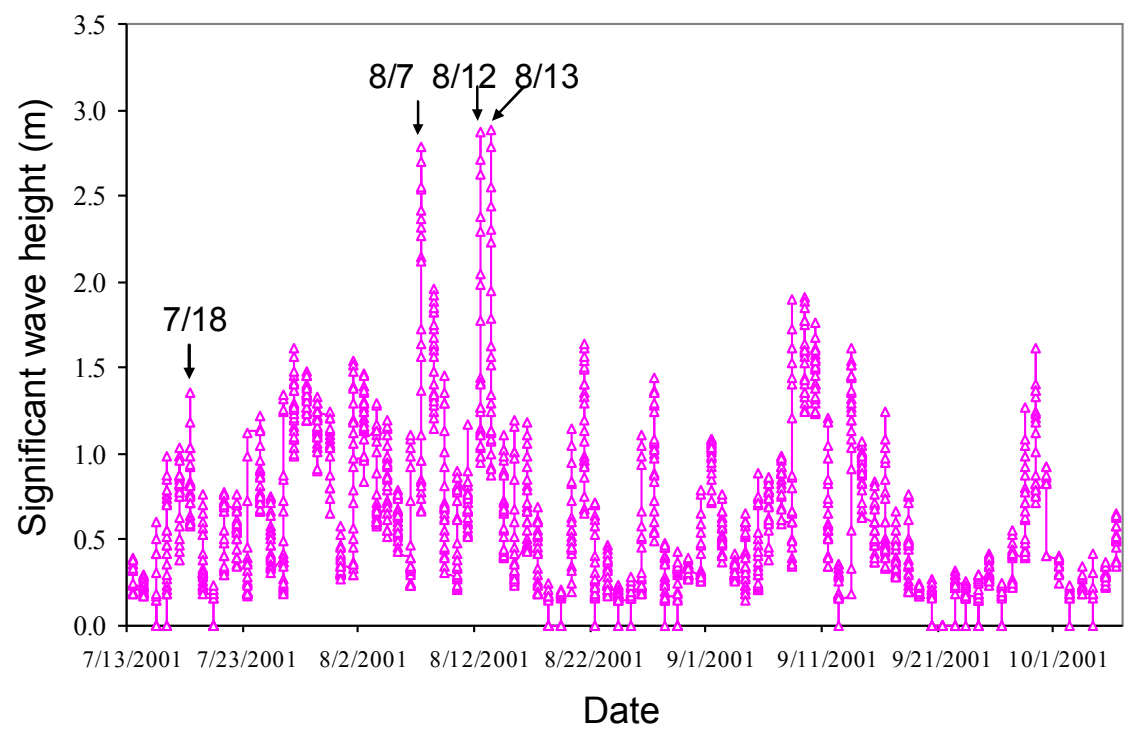

Figure 6. The hourly significant wave height measured at the NOAA's buoy Station 48011 from July 13, 2001 to October 6, 2001 (the daily variation is represented by the vertical length of the line corresponding to the day).

Table 1. Weather Data at Buoy Station 48011 at 10:00 am on July 18, 2001

\begin{tabular}{lllllll}
\hline WD $\left({ }^{\circ}\right)$ & WSPD $(\mathrm{m} / \mathrm{s})$ & GST $(\mathrm{m} / \mathrm{s})$ & WVHT $(\mathrm{m})$ & MWD $\left({ }^{\circ}\right)$ & ATMP $\left({ }^{\circ} \mathrm{C}\right)$ & WTMP \\
201 & 4.9 & 6.1 & 0.93 & 244 & 6.6 & 12.1 \\
\hline WD = wind direction, WSPD = wind speed, GST = gust speed, WVHT = wave height, MWD = mean wave direction, ATMP = air \\
temperature, WTMP = water temperature of sea surface
\end{tabular}

buoy Station 48011 (between July 13 and October 6, 2001) for the year 2001 is shown in Figure 6. Roughness of the sea surface of July 18, 2001 is within the middle range, resulting in the medium surface roughness as indicated by rough water surface mode (Figure 5b).

Within the hour when the image was acquired, the hourly mean air temperature was $6.6^{\circ} \mathrm{C}$ and the sea water temperature at a depth $0.6 \mathrm{~m}$ below sea level is $12.1^{\circ} \mathrm{C}$. The available temperature data at buoy Station 48011 (between July 13 and October 6) for the year 2001 is shown in Figure 7. We can see that before September 27, both air temperature and surface water temperature were well greater than zero. This observation is consistent with the inference from the feature space image (Figure $5 \mathrm{~b}$ ) that there is no ice mode.

\section{Conclusions}

Taking coastal regions of Seward Peninsula and Chukchi Peninsula as a study case, radar feature space images in coastal polar region are formed from radar backscattering coefficient image and look angle image through image processing. Pixel clusters shown in the radar feature space images have specific patterns, showing single mode to multiple modes, as the dynamic processes on the sea ice proceed. Through interprettation of these modes and comparison with NOAA buoy data, we conclude that (1) before sea ice starts to decay and breaks up, mixed landscape and sea ice has a single mode in the feature space image; (2) appearance of multiple modes indicates that dynamic processes, due to either wind field or oceanic circulation or both within the coastal ice zone are active; (3) appearance of open water mode is a deterministic indicator that coastal ice breakup and decay reached a mature stage; (4) land and sea ice modes can be separated when snow and ice on land surface start melting; and (5) calm water surface and rough water surface modes are usually distinguishable in the feature space image due to the strong contrast in backscattering coefficient for the same look angle and the near-linear feature of rough water surface.

Acknowledgments. This work is supported by Montana Space Grant Consortium. We are very grateful to Wade Albright (Alaska SAR Facility) for his help in processing the SAR data, especially in converting the amplitude images to the radiometrically calibrated sigma naught geocoded images using ASF tools.

\section{References}

Bilello, M. (1980). Decay patterns of fast sea ice in Canada and Alaska, in Sea Ice Processes and Models, Proc. of the Arctic Ice Dynamic Joint Experiment Seattle, pp. 313-326.

Brown, R.D. and Cote, P. (1992). Interannual variability of landfast ice thickness in the Canadian High Arctic, 1950-89. Arctic, 45(3), 273-284.

Bump, J.K. and Lovvorn, J.R. (2004). Effects of lead structure in 

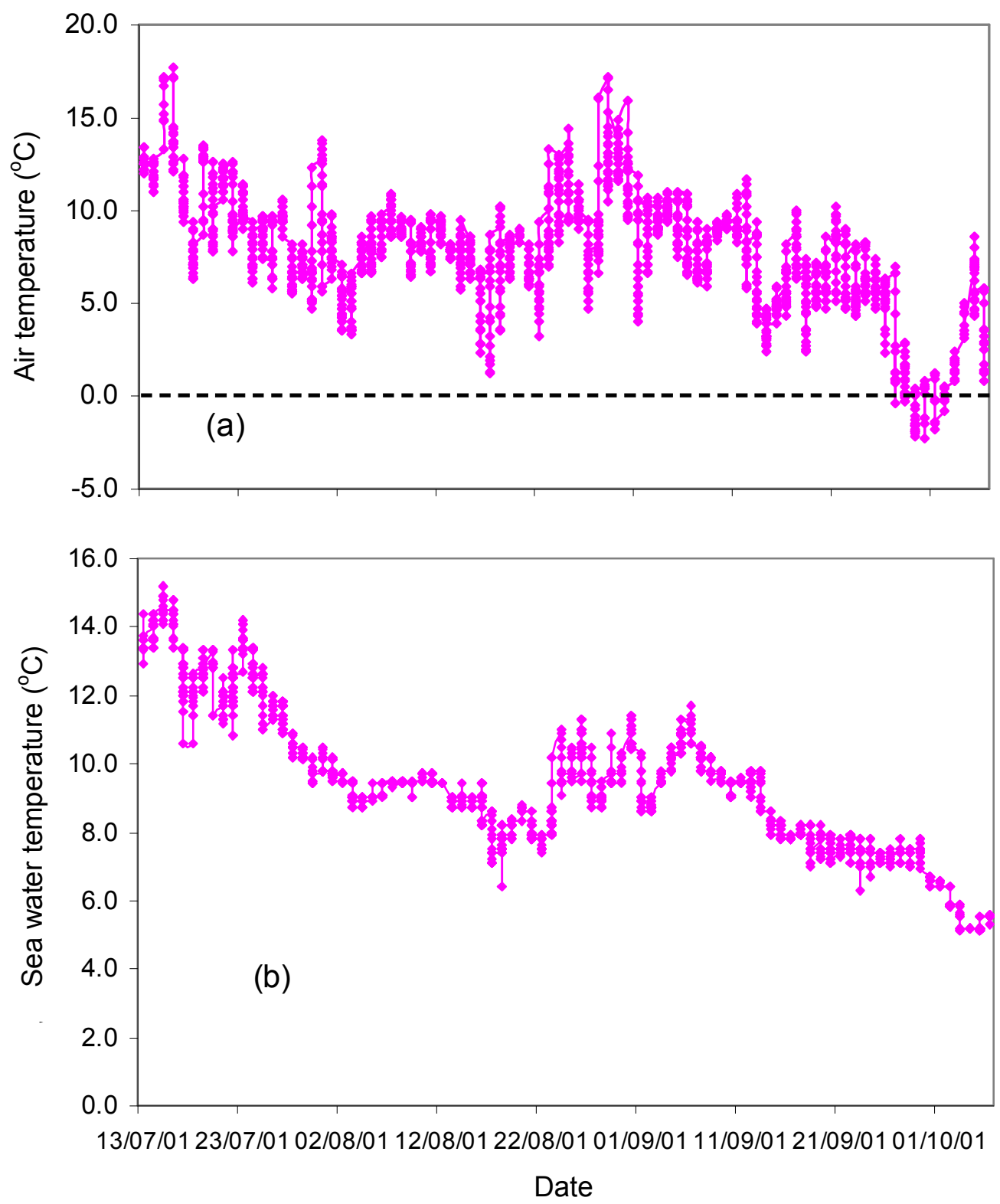

Figure 7. (a) The hourly air temperature, and (b) the hourly sea water temperature measured at the NOAA's buoy station $48011\left(67^{\circ} 34^{\prime} 54^{\prime \prime} \mathrm{N}, 1^{\circ} 4^{\circ} 11^{\prime} 06^{\prime \prime} \mathrm{W}\right)$ from July 13, 2001 to October 6, 2001 (the daily variation of the temperature is represented by the vertical length of the line corresponding to the day).

Bering Sea pack ice on the flight costs of wintering spectacled eiders. J. Mar. Syst., 50(3-4), 113-139.

Chapman, D. (1999). Dense water formation beneath a time dependent coastal Polynya. J. Phys. Oceanogr., 29, 807-820.

Crocker, G. and Wadhams, P. (1989). Breakup of Antarctic fast ice. Cold Reg. Sci. Technol., 17, 61-76.

Cunningham, W.L. and Leventer, A. (1998). Diatom assemblages in surface sediments of the Ross Sea: Relationship to present oceanographic conditions. Antartct. Sci., 10(2), 134-146.

Dethleff, D., Loewe, P. and Kleine, E. (1998). The Laptev sea flaw lead-detailed investigation on ice formation and export during 1991/1992 winter season. Cold Reg. Sci. Technol., 27, 225-243.

Divine, D.V., Korsnes, R. and Makshtas, A.P. (2004). Temporal and spatial variation of shore-fast ice in the Kara Sea. Cont. Shelf Res., 24(15), 1717-1736.

Dmitrenko, I., Golovin, P., Gribanov, V., Kassens, H. and Holeman, J. (1998). Influence of the summer river runoff on ice formation in the Kara and Laptev seas, in Ice in the Surface Waters, Rotterdam, pp.251-257.

Flato, G. and Brown, R. (1996). Variability and climate sensitivity of landfast Arctic sea ice. J. Geophys. Res., 101(C10), 2576725777.

Höfle, C. and Ping, C.L. (1996). Properties and soil development of late-pleistocene paleosols from Seward Peninsula, Northwest Alaska. Geoderma., 71(3-4), 219-243.

Hopkins, D.M. (1959). History of Imuruk Lake, Seward Peninsula, 
Alaska. GSA Bull., 70, 1033-1046.

Hunt, G.L. (1991). Marine birds and ice-influenced environments of polar oceans. J. Mar. Syst., 2, 233-240.

Hunt, G.L., Bakken, V. and Mehlum, F. (1996). Marine birds in the marginal ice zone of the Barents Sea in late winter and spring. Arctic, 49, 53-61.

Jensen, J.R. (2005). Introductory Digital Image Processing: A Remote Sensing Perspective, Prentice Hall, NJ.

Korsnes, R., Pavlova, O. and Godtliebsen, F. (2002). Assessment of potential transport of pollutants into the Barents Sea via sea ice-an observational approach. Mar. Pollut. Bull., 44, 861-869.

Kumar, M. (1993). World geodetic system 1984: A reference frame for global mapping, charting and geodetic applications. Surv. Land Inform. Syst., 53, 53-56.

Kwok, R., Rignot, E., Holt, B. and Onstott, R. (1992). Identification of sea ice types in spaceborne synthetic aperture radar. $J$. Geophys. Res., 97, 2391-2402.

Niebauer, H.J., Bond, N.A., Yakunin, L.P. and Plotnikov, V.V. (1999). An update on the climatology and sea ice of the Bering Sea, in T.R. Loughlin and K. Ohtani (Eds.), Dynamics of the Bering Sea, University of Alaska Sea Grant, Fairbanks, pp. 29-59.

Okkonen, S. and Niebauer, H.J. (1995). Ocean circulation in the Bering Sea marginal ice edge zone from acoustic doppler current profiler observations. Cont. Shelf Res., 15(15), 1879-1902.

Onstott, R.G. (1992). SAR and scatterometer signature of sea ice, in
F.D. Carsey (Ed.), Microwave Remote Sensing of Sea Ice. American Geophysical Union, Washington, DC, 73-104.

Overland, J.E. and Roach, A.T. (1987). Northward flow in the Bering and Chukchi Seas. J. Geophys. Res., 92, 7097-7105.

Patrick, B.E. and Lieberman, J.E. (1988). Thermal overprint on blueschists of the Seward Peninsula, the Lepontine in Alaska. Geol., $16,1100-1103$.

Pease, C.H. (1987). The size of wind-driven coastal polynyas. $J$. Geophys. Res., 92, 7049-7059.

Reimnitz, E., Marincovich, J., McCormick, M. and Briggs, W. (1992). Suspension freezing of bottom sediment and biota in the Northwest Passage and implications for Arctic Ocean sedimentation. Can. J. Earth Sci., 29, 693-703.

Searcy, C., Dean, K. and Stringer, W. (1996). A river-coastal sea ice interaction model: Mackenzie River Delta. J. Geophys. Res., 101(C4), 8885-8894.

Steele, K.E. and Mettlach, T.R. (1993). NDBC wave data-current and planned, in Ocean Wave Measurement and Analysis- Proc. of the Second International Symposium, ASCE, pp. 198-207.

Stirling, I. (1997). The importance of polynyas, ice edges, and leads to marine mammals and birds. J. Mar. Syst., 10, 9-21.

Volkov, V., Johannessen, O., Borodachev, V., Voinov, G., Pettersson, L., Bobylev, L. and Kouraev, A. (2002). Polar seas oceanography, An Integrated Case Study of the Kara Sea, Springer, London. 